Document downloaded from:

http://hdl.handle.net/10251/148097

This paper must be cited as:

Desantes, J.; García-Oliver, JM.; García Martínez, A.; Xuan, T. (2019). Optical study on characteristics of non-reacting and reacting diesel spray with different strategies of split injection. International Journal of Engine Research. 20(6):606-623.

https://doi.org/10.1177/1468087418773012

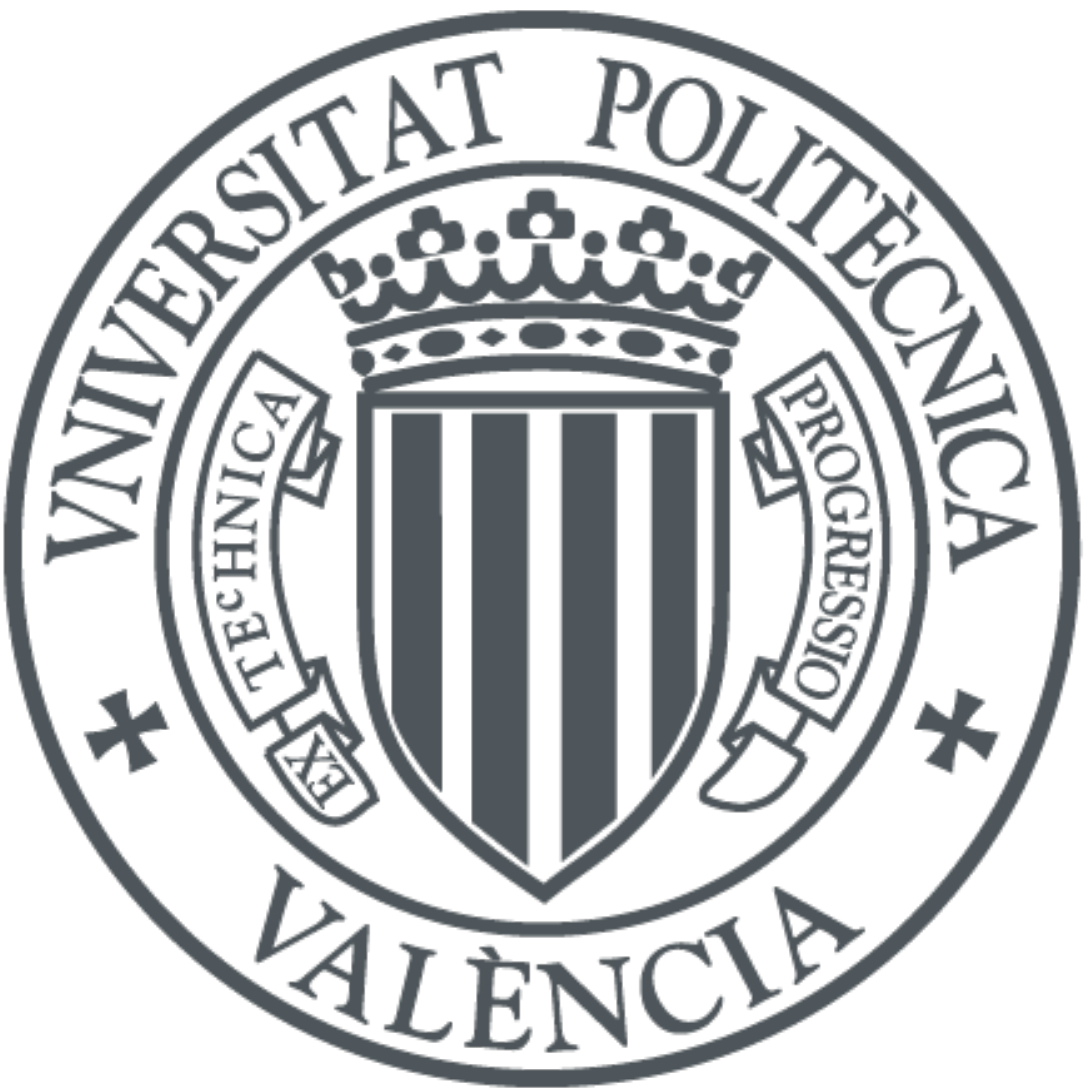

The final publication is available at

https://doi.org/10.1177/1468087418773012

Copyright SAGE Publications

Additional Information 


\title{
Optical study on Characteristics of Non- reacting and Reacting Diesel Spray with Different Strategies of Split-Injection
}

\author{
J.M. Desantes ${ }^{1}$, J.M. García-Oliver ${ }^{1}$, A. García ${ }^{1}$ and T. Xuan ${ }^{1 *}$ \\ 1 CMT-Motores Térmicos. Universitat Politècnica de València, Valencia, Spain \\ * Corresponding author: CMT-Motores Térmicos. Universitat Politècnica de València. Camino de Vera, s/n \\ 46022 Valencia (Spain) Email: tiexua@mot.upv.es
}

\begin{abstract}
Even though studies on split-injection strategies have been published in recent years, there are still many remaining questions about how the first injection affects the mixing and combustion processes of the second one by changing the dwell time between both injection events or by the first injection quantity. In this paper, split-injection Diesel sprays with different injection strategies are investigated. Visualization of n-dodecane sprays was carried out under both non-reacting and reacting operating conditions in an optically accessible two-stroke engine equipped with a single-hole Diesel injector. Highspeed Schlieren imaging was applied to visualize the spray geometry development, while Diffuse Back Illumination (DBI) was applied to quantify the instantaneous soot production. For non-reacting conditions, it was found that the vapor phase of second injection penetrates faster with a shorter dwell time, and independently of the duration of the first injection. This could be explained in terms of 1D spray model results, which provided information on the local mixing and momentum state within the flow. For reacting conditions, dwell time and first injection quantities have a relatively low significant effect on the ignition delay and lift-off length of the second injection, mainly due to the similar flow conditions in the vicinity of the nozzle. However, soot production behaves different with different injection strategies. The maximum instantaneous soot mass produced by the second injection increases with a shorter dwell time and with longer first injection duration.
\end{abstract}

\section{KEYWORDS}

Diesel spray, split-injection, vapor penetration, ignition delay, soot

\section{INTRODUCTION}

Multiple injection strategies have been studied and widely applied in conventional diesel engines in past decades because of a lot of benefits which they can bring on emissions and fuel economy ${ }^{1-6}$. Nowadays, the injection timing and fuel quantity distribution can be controlled in a flexible way thanks to the high pressure electronically-controlled common rail systems. Pilot injections are usually employed to soften the combustion of main injection, which can reduce in-cylinder temperature and the rise rate of in-cylinder pressure. As a consequence, the reductions in thermal NOx emission and engine noise 
can be achieved ${ }^{1,2,7,8}$. On the other hand, post injections after the main pulse are usually applied to reduce unburned hydrocarbon (UHC) and soot formation. With increased entrainment of ambient gas after end of injection (EOI), vapor-fuel mixtures near the injector transition from fuel-rich to fuel-lean and the flow decelerates pretty fast, which causes it to stagnate near the injector, contributing to incomplete combustion and UHC ${ }^{9-}$ 11. Post injection can push the residual lean mixture near the nozzle downstream and reach second-stage combustion with higher equivalence ratio and higher temperature environment ${ }^{12}$. In addition, it has been proved that the engine-out soot can be reduced by post injection with a proper dwell time and quantity ${ }^{12-14}$.

Because of the complexity of the interaction mechanism among these multiple injection pulses, many researchers have investigated the physical phenomena with relatively simple split-injection strategies, i.e. with only two injection pulses. The characteristics of non-reacting split-injections have been studied experimentally in ${ }^{15-17}$. Both Bruneaux ${ }^{15}$ and Skeen ${ }^{17}$ show that the vapor phase of second injection enters a "slipstream", which makes it penetrate faster than that of the first one. This phenomenon has also been well reproduced by CFD modelling ${ }^{18,19}$. Thanks to velocity measurement, Bruneaux has also found that the interaction between two injection pulses is stronger with a shorter dwell time, leading to an increase of the mixing rate at the head of second spray. In addition, the liquid-phase penetration of the second injection has also been found to be longer than the first one when the pulse duration has been kept constant, and both injections end before the liquid-phase can reach the steady-state liquid length ${ }^{16}$. As for reacting sprays, the ignition processes of split-injection under different ambient temperature have been studied in detail by Skeen in a pre-burn combustion vessel with nDodecane as a fuel ${ }^{17}$. In general, the ignition delay (ID) of the second injection is reduced by a factor of two or more relative to that of the first injection, which is caused by the entrainment of high temperature combustion products and radical species remaining from first injection. The effects on ignition delay of dwell time between double injections have been also presented in ${ }^{21,22}$. However, more detailed analysis is still needed to be studied. The transient flame lift-off length (LOL) development of splitinjection has been recently measured by Maes ${ }^{20}$ by means of the high-speed $\mathrm{OH}^{*}$ chemiluminescence. It is interesting to see that LOL slowly progresses further downstream after ignition of the second injection until the combustion recession takes place after EOI. Moiz et, al. have investigated the effect of changing dwell time on transient soot formation by means of CFD simulation ${ }^{23}$. In their work, the decrease in soot production with longer dwell time has been explained by a higher air-entrainment. The experimental validation and more possible factors that contribute to soot production need to be further studied.

The aim of this paper is to provide a detailed analysis of the effects of dwell time and first injection quantity sweep on the characteristic of second injection under both non-reacting and reacting conditions by means of different optical techniques and a 1D spray model ${ }^{24,25}$. High-speed Schlieren imaging has been used to visualize the vapor penetration of double injections as well as the LOL, while the temporal soot production has been measured by a diffused background-illumination extinction imaging (DBI). In addition, the apparent heat release rate (AHRR) derived from cylinder pressure is also used for the analysis. This work is a follow-up of a study as in ${ }^{26}$ in which extensive 
experimental tests were done to study the single spray characteristics with the same test rig. Therefore, experimental tools are certainly the same. 1D spray modelling has been added to improve the complex analysis of interaction between injection pulses.

\section{EXPERIMENTAL TOOLS}

Because experimental tools are the same as in ${ }^{26,27}$, a brief review is presented here. For more details, the reader should address the previous reference.

\subsection{EXPERIMENTAL FACILITY}

An optically accessible single cylinder two-stroke engine with three-liter displacement, 15.6:1 compression ratio and low rotational speed of $500 \mathrm{rpm}$ has been used for these experiments. The cross-sectional view of cylinder head is shown in Fig. 1. The geometrical parameters of the combustion chamber, the size of optical windows and operating methods are detailed in ${ }^{26,27}$. A Bosch common-rail solenoid injector equipped with a single-hole nozzle $0.082 \mathrm{~mm}$ in diameter was used in this study.

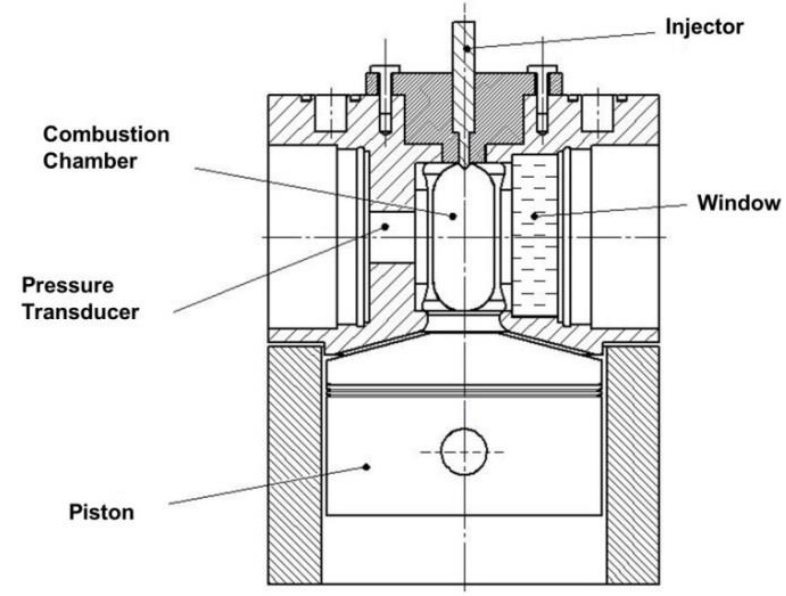

Fig. 1 Cross-sectional view of cylinder head

\subsection{OPTICAL TECHNIQUES}

High-speed Schlieren imaging was applied here for measuring the vapor penetration under non-reacting conditions. The schematic of the corresponding optical setup is shown in Fig. 2 (a). As for reacting cases, the Schlieren technique was also used to visualize transient spray structure development and quantify the flame lift-off length. Additionally, DBI was applied to measure soot formation. The schematic of the corresponding optical setup is shown in Fig. 2 (b). Due to the spatial separation between the liquid part of the spray and the flame under the investigated conditions, DBI could also be used to quantity the liquid length. Both Schlieren and DBI were measured in independent runs because of limitations in the optical accesses. 


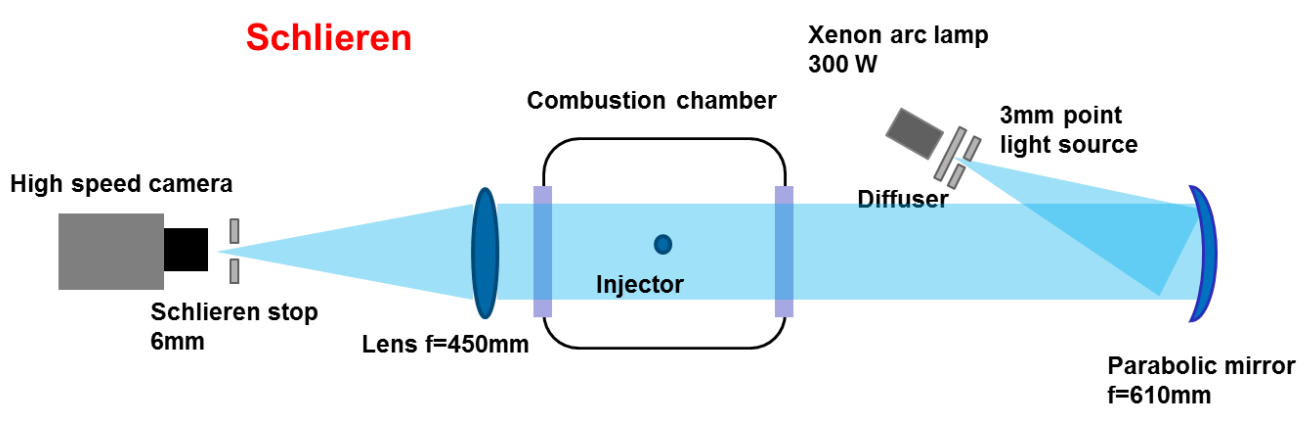

(a)

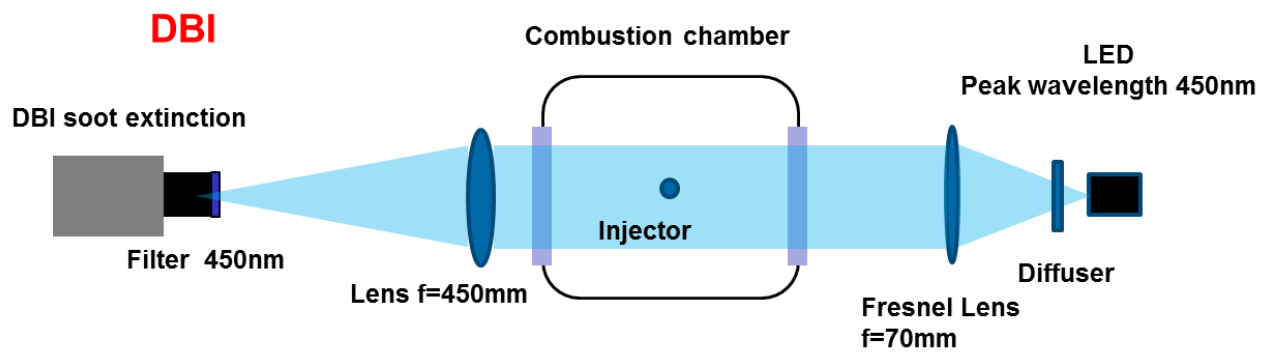

(b)

Fig. 2 Optical setup (a) high speed Schlieren (b) DBI

\subsubsection{Schlieren imaging}

Schlieren imaging is a valuable technique for identifying density gradients, from which the spray area can be derived because of the density difference between vaporized fuel and ambient gases. The technique is based on the deviation suffered by a light beam, due to the change in refraction index of the media, which will be related to the local density gradient ${ }^{28}$. This effect is known as beam steering. In addition, besides spray tip penetration, the temporal averaged flame lift-off lengths for both first and second injection have been also obtained from Schlieren images based on the analysis on the spray radial increment between each two positions away from the nozzle tip with 5 pixel interval. The corresponding position where the peak of the radial increment takes place is defined as LOL. Measurement of LOL by means of Schlieren technique has been coincident with that of low-speeed $\mathrm{OH}^{*}$ chemiluminiscence imaging for Spray A experiments when ambient temperature is higher than $800 \mathrm{~K}$ at a density of $22.8 \mathrm{~kg} / \mathrm{m}^{3} 29$. One example of the LOL from Schlieren imaging is shown in Fig. 3. The detailed information about the optical components and camera settings has been presented in ${ }^{26}$. 


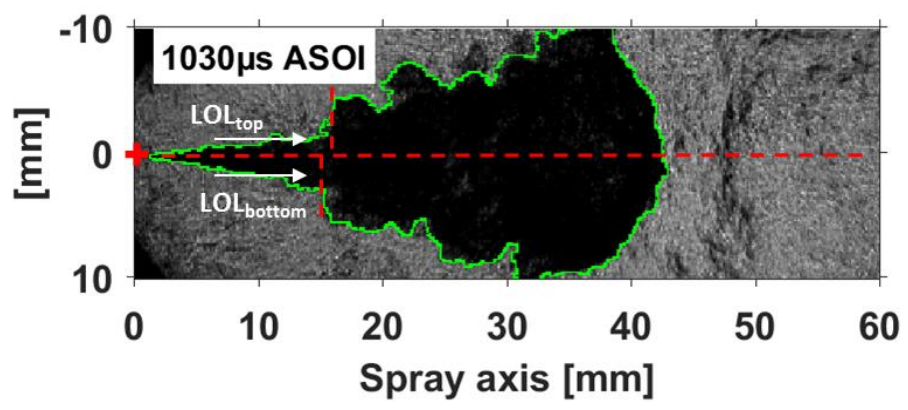

Fig. 3 Schematic of LOL from Schlieren imaging

\subsubsection{Diffused Background-illumination Extinction Imaging}

The DBI optical setup (Fig. 2(b)) and all optical components are pretty similar with the ones in reference ${ }^{30}$. The only difference is the camera settings. Here, the exposure time of the camera was set to $6.62 \mu$ s with $264 \times 640$ pixels image resolution running at $35 \mathrm{khz}$ and the pixel/mm ratio is 7.71 . The theoretical knowledge about this technique, the detailed configuration of the setup and the processing methodology to obtain the soot optical thickness (KL) can be referenced from ${ }^{30}$.

The primary measured variable is the optical thickness $K L$ which, according to the small particle Mie theory ${ }^{31}$, is an integral value of soot volume fraction $\left(f_{v}\right)$ along the line-of-sight. The relationship between $K L$ and $f_{v}$ is shown as follows:

$$
K L=\int \frac{k_{e}}{\lambda} f_{v} d l
$$

and

$$
k_{e}=\left(1+\alpha_{s a}\right) \cdot 6 \pi \cdot E(m)
$$

where $\lambda$ is the wavelength of the incident illumination, $k_{e}$ is the dimensionless extinction coefficient, $\alpha_{s a}$ is the scattering-to-absorption ratio, $m$ is the refractive index of soot. $k_{e}$ can be obtained from the Rayleigh-Debye-Gans (RDG) theory as $k_{e}=7.61$. The details of the RDG theory and all the parameters used for calculating the $k_{e}$ are referenced from 32,33 . From the measured KL, the sum of soot mass $\left(\mathrm{m}_{\text {soot }}\right)$ along the line-of-sight at each pixel was derived from eq.(3) using an assumed density of $1.8 \mathrm{~g} / \mathrm{cm}^{3}$ for soot $\left(\rho_{\text {soot }}\right)^{34}$.

$$
m_{\text {soot }}(x, y, t)=\rho_{\text {soot }} K L(x, y, t) \frac{\lambda}{k_{e}}
$$

Uncertainties on this soot mass are present because of the assumptions used for calculating $k_{e}$ and the assumed uniformed soot density. Furthermore, beam steering exists because of the imperfect Lambertian light source, which determines the lower KL detection limit (lower than 0.05 as mentioned in ${ }^{30}$ ). The line-of-sight soot mass map obtained from eq (3), can be integrated along the radial direction of spray to obtain a onedimensional time-dependent soot distribution according to 


$$
m_{\text {soot }}(x, t)=\int_{-y_{1}}^{y_{2}} m_{\text {soot }}(x, y, t) d y
$$

where $x$ is the spray axial direction, $y$ is the spray radial direction, $y_{1}$ and $y_{2}$ are the spray boundary positions.

One example of a $m_{\text {soot }}(x, y, t)$ map at $1.6 \mathrm{~ms}$ is shown in Fig. 4, together with a derived $m_{\text {soot }}(x, t)$ map for a Single-injection case. The AHRR and corresponding ID, as calculated in the next section, are also presented in these plots with black line and vertical blue line respectively. The injection duration is indicated with a grey line. From Fig. 4 soot takes place after a short dwell time from ignition delay (soot onset time) and a minimum distance to the nozzle (soot onset length). The latter distance stabilizes around $28 \mathrm{~mm}$, which is farther downstream than that of flame lift-off length (near $15 \mathrm{~mm}$ as shown in later section). The boundary of this soot cloud represents the place where the soot is oxidized completely within the limitation this optical technique. No clear soot recession was found after end of injection.

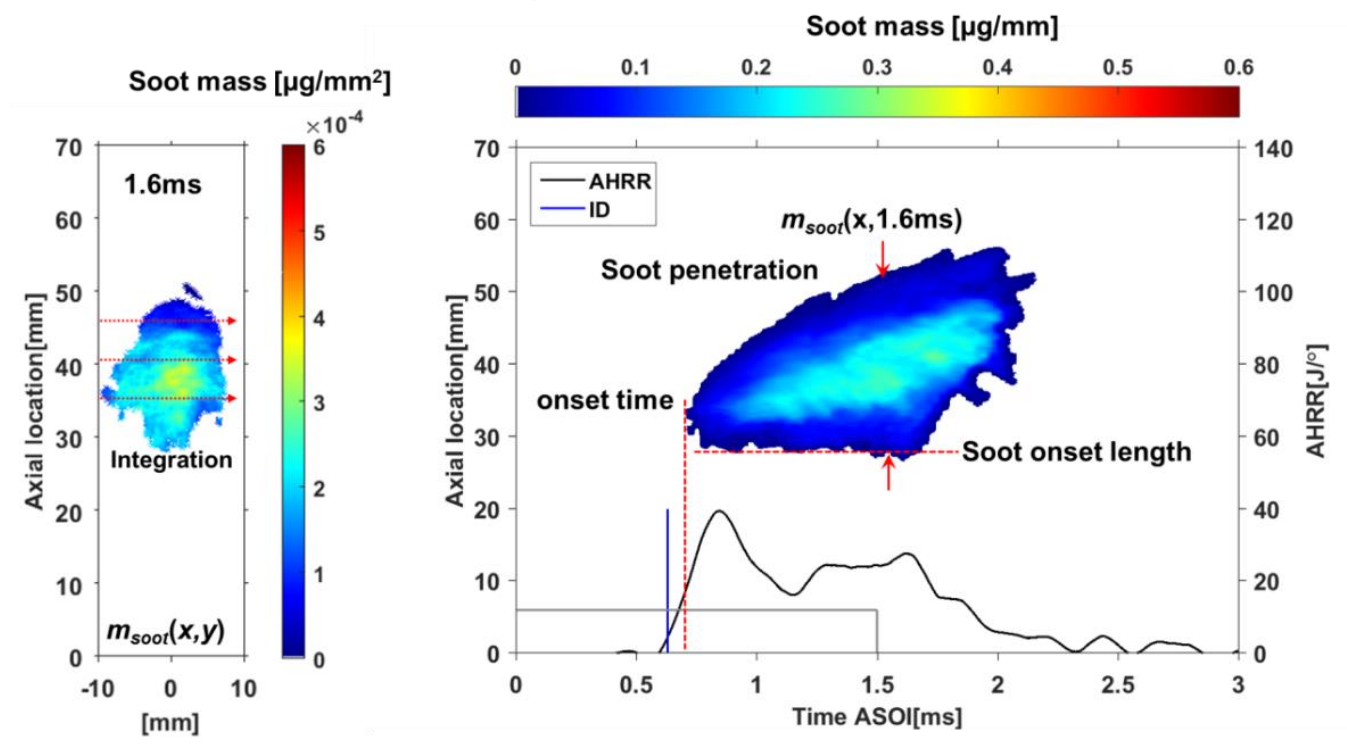

Fig. $4 \mathrm{~m}_{\text {soot }}(\mathrm{x}, \mathrm{y}, \mathrm{t}), \mathrm{m}_{\text {soot }}(\mathrm{x}, \mathrm{t})$ plot, AHRR and ignition delay of Single_1500 case.

As mentioned above, the liquid length was also quantified from DBI images following the approach recommended from Engine Combustion Network (ECN) ${ }^{35}$. The only difference is that the temporal liquid length evolution was obtained here from images averaged from 40 repetitions at each time position rather than just one timeaveraged value. The details of this processing methodology can be found ${ }^{36}$.

\subsection{Apparent Heat Release Rate}

According to the first law of thermodynamics, the AHRR is derived from cylinder pressure trace, which is obtained from a high-speed piezoelectric transducer installed in the combustion chamber, as shown in the following equation ${ }^{37}$ : 


$$
\frac{d Q}{d t}=P \frac{d v}{d t}+m c_{v} \frac{d T}{d t}
$$

where $P$ is the cylinder pressure, $v$ is the volume of combustion chamber, $m$ is the fuel mass, $T$ is the cylinder temperature, $c_{v}$ is the specific heat at constant volume.

One example of AHRR is shown in Fig. 4 (right). Ignition delay of first injection (ID1) was defined as the first instant when AHRR exceeds $15 \%$ of the first peak. For the second injection, ignition delay (ID2) corresponds to the time at which the AHRR increases above $15 \%$ of the second peak from the minimum value between the two peaks. Ignition delay values shown throughout the paper are a robust average of the ID calculated from AHRR of each cycle rather than a single value from the AHRR derived from the averaged pressure signal.

\section{THEORETICAL TOOLS. 1D SPRAY MODEL}

A previously existing 1D spray model ${ }^{24,25}$ has been used to substantiate the analysis of experimental results. The model solves 1D conservation equations of axial momentum and mixture fraction in terms of the axial distance to the nozzle. Radial evolution is considered by means of radial integral terms in the model by assuming a Gaussian self-similar profile. The model has been successfully used to predict inert spray penetration and liquid length ${ }^{24}$. Compared to similar models in the literature, where local density is assumed to be radially homogeneous ${ }^{38,39}$ and is not always coupled into the momentum equations ${ }^{39}$, the present approach feeds local density from state relationships into conservation equations from the radial distribution of mixture fraction. This makes it possible to include the effects of heat release by modifying the distribution of local density as a consequence of heat release, which will result in a modified velocity distribution.

Under inert conditions, inputs for the model are

- Fuel mass and momentum fluxes at the nozzle orifice.

- Fuel composition, temperature and density.

- Ambient gas composition, pressure, temperature and density.

- Spray cone angle.

When dealing with reacting conditions, a simplified Burke-Schuman approach ${ }^{40}$ is followed, with a single-step reaction assumed for chemistry. Due to the absence of chemical kinetic effects, which would enable the prediction of ignition delay and lift-off length, two additional inputs for the model are

- Ignition delay to identify when combustion will start. The 1D model assumes that a step transition from inert to reacting conditions occurs at the experimental ignition delay.

- On-axis mixture fraction at the lift-off length, which will enable the model to spatially separate the location where the spray transitions from inert to reacting 
conditions. This is usually derived from the experimental lift-off length distance, and a model calculation under inert condition, and can be converted later to equivalence ratio at the lift-off length.

In addition to the previous parameters, information on the radial expansion process as a consequence of the transition from inert to reacting states has to be included, as presented in ${ }^{41}$.

\section{TEST MATRIX AND EXPERIMENTAL METHODOLOGY}

The test matrix is summarized in Table 1, Injection pressure was kept constant at 1500 bar. Note that all injection duration times within the present paper are defined in terms of actual injection duration, which was determined by observation from high speed camera images, i.e. they do not refer to energizing times. The dwell time is the interval between the end of the first injection and the start of the second injection. Two single injection cases, with $500 \mu \mathrm{s}$ and $1500 \mu \mathrm{s}$ injection duration separately, were also measured and analyzed in this study as a reference. As for dwell variation, two points (D250 and D750) were conducted with same injected quantities for both injections (500 $\mu \mathrm{s})$ but changing the dwell from $250 \mu \mathrm{s}$ to $750 \mu \mathrm{s}$. As for the first injection quantity variation, the injection duration could not be set shorter than $500 \mu \mathrm{s}$ because of the limitation of the electronic control. The first injection duration changes from $500 \mu \mathrm{s}$ (F500) to $750 \mu \mathrm{s}$ (F750), while the dwell time and the second injection duration were fixed at $500 \mu \mathrm{s}$ and $1000 \mu \mathrm{s}$, respectively. The first 4 points in Table 1 were measured under non-reacting (fuel is injected into a gas mixture containing pure nitrogen) and reacting conditions (injection is performed into ambient air, with $21 \%$ oxygen (vol.)), while the last two points were only measured under reacting conditions.

Table 1 Test Matrix

\begin{tabular}{|c|c|c|c|c|c|c|c|}
\hline $\begin{array}{l}\text { Operating } \\
\text { point }\end{array}$ & Oxygen[\%] & $\begin{array}{l}\text { Injection } 1^{\text {st }} \\
{[\mu \mathrm{s}]}\end{array}$ & $\begin{array}{l}\text { Mass } 1^{\text {st }} \\
{[\mathrm{mg}]}\end{array}$ & $\begin{array}{l}\text { Dwell } \\
{[\mu s]}\end{array}$ & $\begin{array}{l}\text { Injection } 2^{\text {nd }} \\
{[\mu s]}\end{array}$ & $\begin{array}{c}\text { Mass } 2^{\text {nd }} \\
{[\mathrm{mg}]}\end{array}$ & Comments \\
\hline Single_500 & $0 / 21$ & 500 & 0.8 & - & - & - & \\
\hline Single_1500 & $0 / 21$ & 1500 & 2.6 & - & - & - & $\begin{array}{c}\text { Single } \\
\text { injection }\end{array}$ \\
\hline D250 & $0 / 21$ & 500 & 0.8 & 250 & 500 & 0.8 & \\
\hline D750 & $0 / 21$ & 500 & 0.8 & 750 & 500 & 0.8 & $\begin{array}{c}\text { Dwell } \\
\text { variation }\end{array}$ \\
\hline F500 & 21 & 500 & 0.8 & 500 & 1000 & 1.4 & $\begin{array}{c}\text { First } \\
\text { injection }\end{array}$ \\
\hline F750 & 21 & 750 & 1.1 & 500 & 1000 & 1.4 & $\begin{array}{l}\text { duration } \\
\text { variation }\end{array}$ \\
\hline
\end{tabular}

In-cylinder conditions were the same for all operating conditions, namely those corresponding to a TDC density of $22.8 \mathrm{~kg} / \mathrm{m}^{3}$ and a temperature of $870 \mathrm{~K}$. To determine 
the intake pressure and temperature values required to achieve the target TDC conditions, an accurate characterization of the engine has been performed, details can be found in ${ }^{42}$. In-cylinder thermodynamic conditions have been calculated from measured pressure and an analysis based upon the ideal gas law and the first-law of thermodynamic. In-cylinder temperature and density temporal evolution during the injection event are plotted in Fig. 5 . The injector was energized starting at $-6.35^{\circ}$ ATDC, while the actual injection starts at around $-5.35^{\circ}$ ATDC, to minimize piston-induced volume variations conditions during the injection event. The longest injection event from above test matrix lasts $2.25 \mathrm{~ms}$ approximately (F750), presented as red dashed lines. In other words, all injection events mentioned above happened within this time interval. The density and temperature differences during the whole injection event are smaller than $1 \mathrm{~kg} / \mathrm{m}^{3}$ and $12 \mathrm{~K}$, respectively. Thus, their influence will be considered negligible.

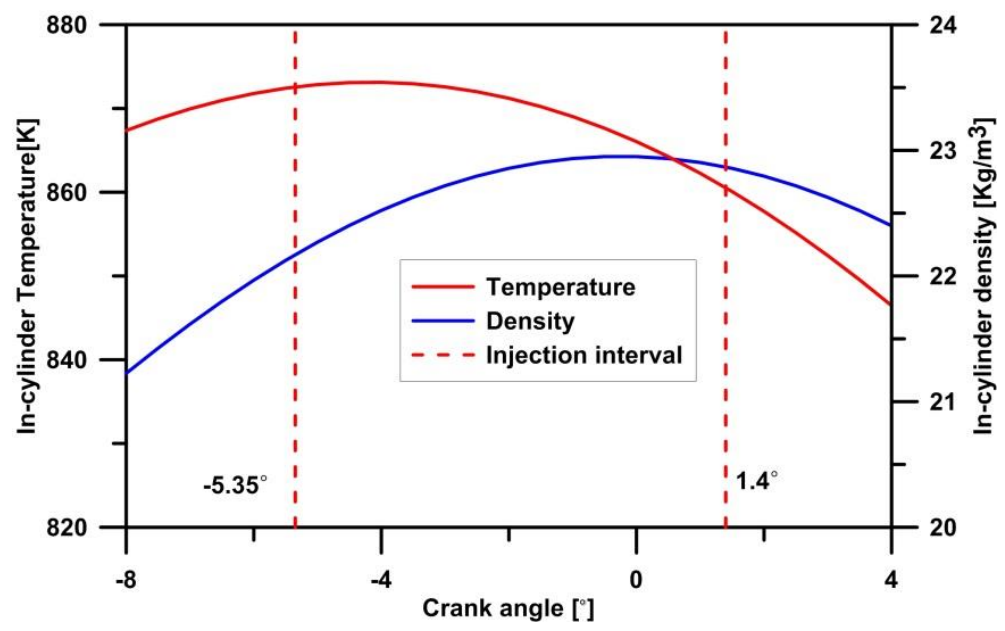

Fig. 5 Thermodynamic in-cylinder conditions along engine cycle

Fuel used throughout the tests was n-Dodecane, which has been selected as the referenced fuel for ECN experiments. At each operating condition within the present study, 30 injections have been recorded for Schlieren tests and 40 injections have been recorded for soot tests (considering the higher cycle-to-cycle scattering for soot production) to reduce measurement uncertainties due to engine operating variability.

The injection mass flow rate was measured using commercial long-tube equipment. The measuring principle used is the Bosch method ${ }^{43,44}$, which consists of a injector that injects the fuel into a fuel filled measuring tube. A total of 50 repetitive measurements were carried out for each operating point. In order to avoid noise interference from real experimental data, and reduce its effect on the 1D modeling, the mass flow rate was standardized with a model provided in ${ }^{45}$. One example of both experimental and modeled mass flow rate curves for the single long injection case is shown in Fig. 6. The spray momentum flux as an input in the 1D modeling was calculated from modeled mass flow rate and area and velocity coefficients for this injector obtained in previous research ${ }^{42}$. 


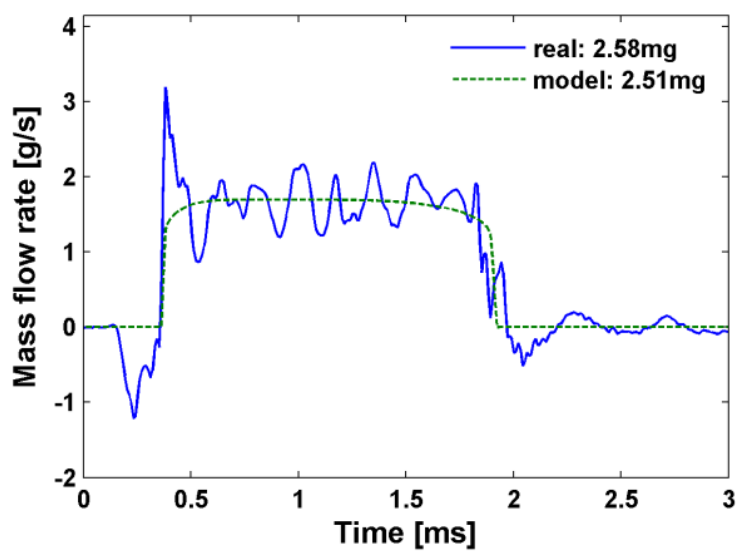

Fig. 6 Experimental and modeled mass flow rate for Single_1500 operating point.

\section{RESULTS AND DISCUSSION}

\subsection{Non-reacting spray analysis}

A time sequence of processed Schlieren images from one individual cycle and its corresponding simulated equivalence ratio contours for Single_1500 and D250 cases under non-reacting condition are provided in Fig. 7. Additionally, in Fig. 8 the measured penetration, as well as the modelled one have been plotted against time. The detected contours are overlaid on the images to highlight the measured penetration. From the processed contours of Single_1500 case (left) one can observe that when the spray tip reaches around $40 \mathrm{~mm}$ away from the nozzle, the detection of the spray is not accurate enough, as it gets diluted into the noisy background caused by the high velocity motion of airflow from the piston movement. The detailed analysis of this airflow influence on spray development has already been included in ${ }^{26}$, where the spray evolution is shown to be slowed down due to the interaction with a high-velocity area on the region located around $40 \mathrm{~mm}$ from the nozzle. Fig. 8 shows that the 1D model can predict the spray tip quite accurately before it reaches $40 \mathrm{~mm}$ because of the negligible airflow effect during this period. However, the model starts over predicting the spray tip penetration after 40 $\mathrm{mm}$. This is consistent with the fact that the model simulates a spray being injected into a quiescent chamber, and therefore any deviation from this situation results in the model not being able to predict the spray event. According to the mentioned deviation of penetration by the model, the effect of the flow hints at a slower spray evolution compared to a quiescent environment, which is consistent with previous results ${ }^{26}$. Therefore, 1D model predictions of the spray until $40 \mathrm{~mm}$ should be considered as reliable.

As for the D250 case (Fig. 7, right), the second injection appears at $797 \mu$ s after start of injection (ASOI) from Schlieren images. During the first instants, the remaining density gradients of spray head from first injection makes the processing routine still capture the first injection tip rather than the second spray. When such density gradients disappear, the second injection spray is properly detected (e.g. $997 \mu \mathrm{s} \mathrm{ASOI).} \mathrm{After} \mathrm{the}$ end of each injection (797 $\mu \mathrm{s}, 1597 \mu \mathrm{s}$ ASOI), the entrainment wave phenomenon ${ }^{11}$ 
leads to a fast leaning out of the spray. Fig. 7 also shows the equivalence ratio contours as derived from the 1D model. For single injection case, equivalence ratio at spray tip drops with time gradually after EOI. But for the D250 case, the second injection can be easily identified by the rich mixture pulse evolving within the lean mixture field created by the first pulse. As a consequence, the $\Phi=1$ contour was applied for quantifying tip penetration of second injection and it can only be obtained when the equivalence ratio of first injection becomes smaller than 1 . In addition, it is interesting to observe that the stagnant mixture remaining near the injector caused by the entrainment wave from both injections was also captured by this model (795 $\mu$ s ASOI, $1594 \mu$ s ASOI), which might contribute to a combustion recession, UHC or more soot formation for the second injection. This will be discussed in detail in the reacting spray section.
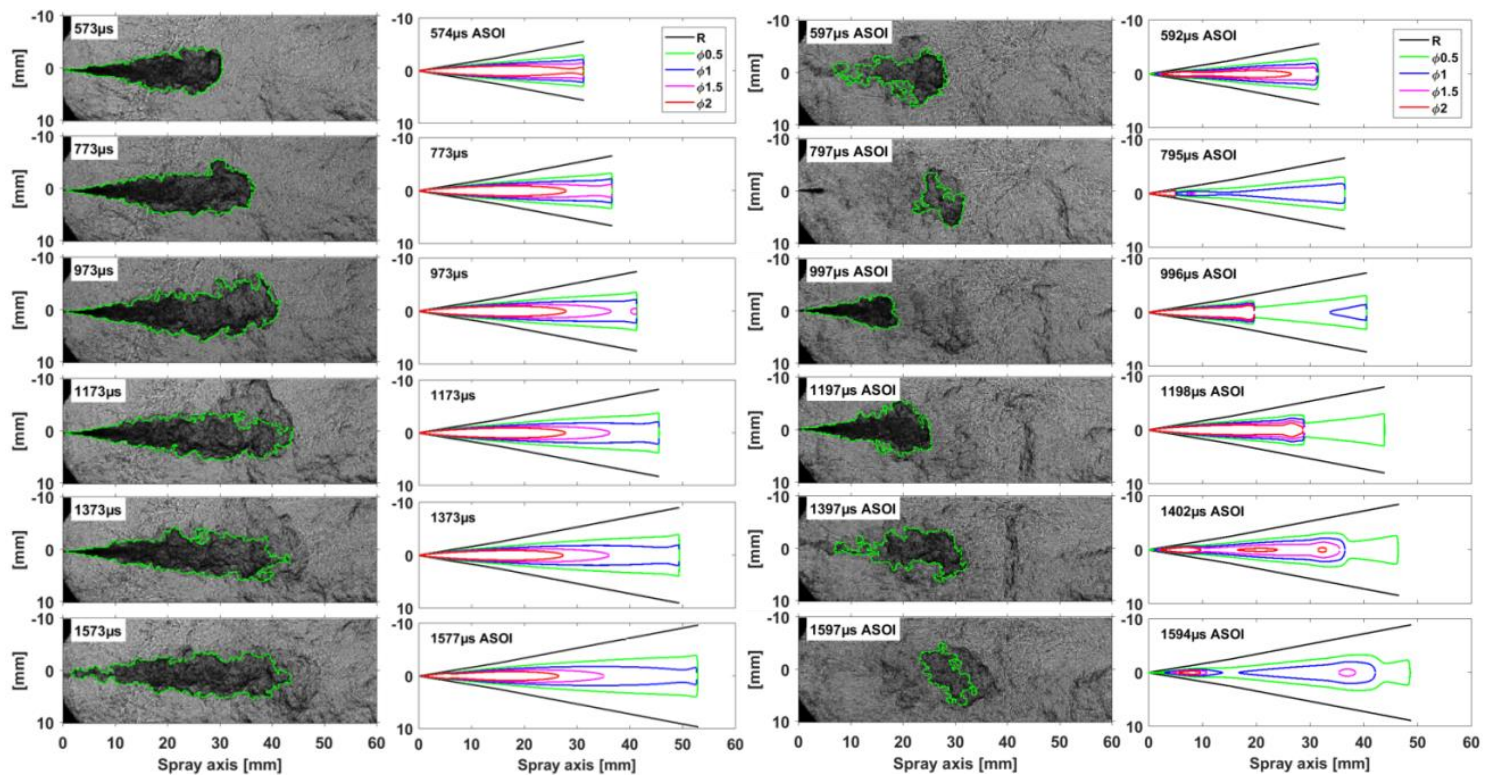

Fig. 7 Time sequence of Schlieren images and corresponding equivalence ratio contours derived from the model for Single_1500 (left) and D250 (right) cases. R represents the spray boundary.

The comparison for vapor and liquid penetration between experimental and modeling results are shown in Fig. 8. It has to be noted that the experimental liquid length in these plots is from DBI tests under reacting conditions. However, for all three cases no difference can be observed in the liquid length (LL) behavior before and after start of combustion, as liquid fully vaporizes before the lift-off length. Hence this information is also used here for non-reacting spray model validation. Fig. 8 shows a very good agreement between modeling and experimental results on both vapor penetration (below $40 \mathrm{~mm})$ and liquid length. 

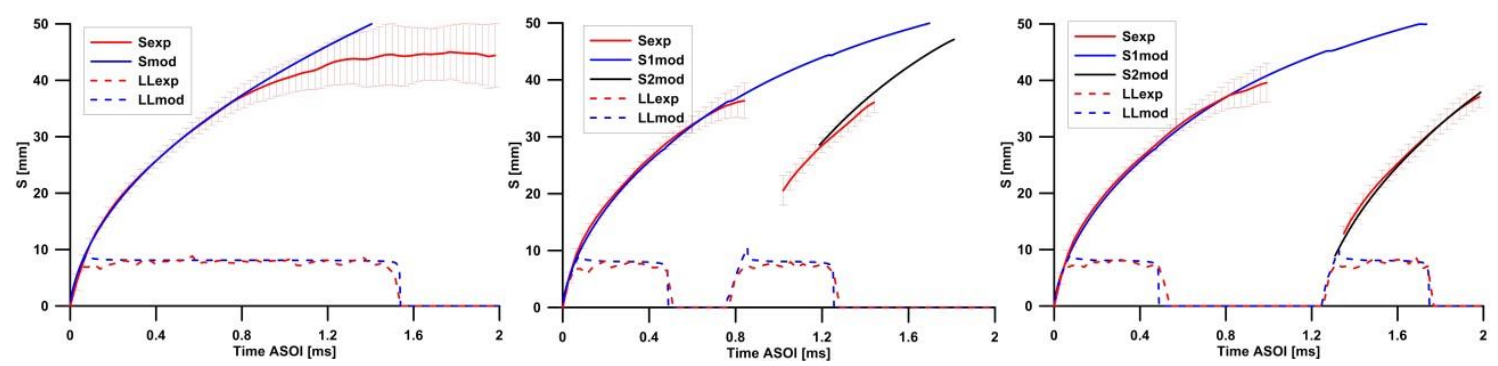

Fig. 8 Vapor (solid line) and liquid (dashed line) penetration of Silgle_1500 (left), D250 (middle) and D750 (right) cases from both experiment and model. Vapor penetration corresponds to inert cases, while liquid one has been derived from reacting cases. However, no effect can be observed in the latter cases due to combustion. For the vapor penetration, error bars correspond to \pm standard deviation.

To study how the first injection affects the second one, the time base was shifted, so that the origin was set at the start of second injection, and the new time base is expressed in time units after start of second injection (ASOI2). The mass flow rates are shown in Fig. 9 to help explain the time shift and the definition of ASOI2. Two single injection cases of Single_500 and Single_1000 are also used as references for further analysis. The Single_1000 is a case of single injection with $1000 \mu$ s injection duration, which mimics the second pulse of the F500/F750 cases. This condition was not measured experimentally, but modelling is used here for the analysis. .
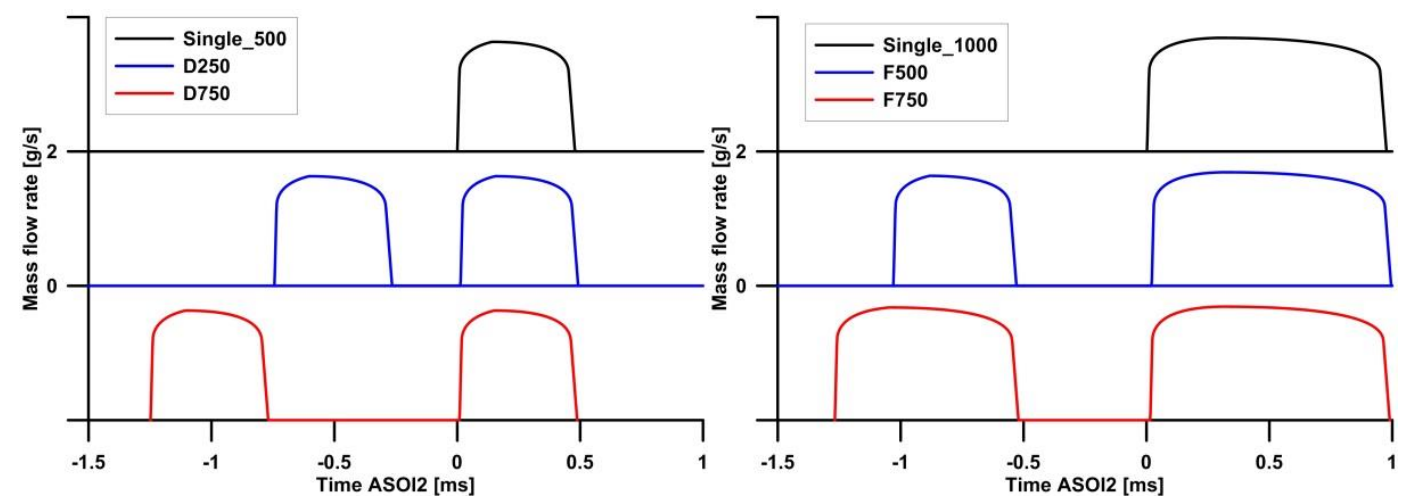

Fig. 9 Injection rate plot with a shifted time base to show the definition of the timing "after start of second injection" (ASOI2). Dwell (left) and first injection duration (right) variations are shown.

Fig. 10 shows the vapor penetration of the second injection for dwell variation cases from both experiments (left) and modeling (right). Vapor penetration of Single_500 is also shown here as a reference, which presents the same penetration evolution as the first injection of both dwell variation cases. Vapor penetrations of first injection for cases D250, D750 and Single_500 overlap with each other until the corresponding end of injection because their injection rates are identical. Both experiments and modelling show a consistent trend in terms of the second injections penetrating faster than single one after some axial distance because of the "slipstream" 15,17 effect. As for parametric trends, the second injection penetrates faster with a shorter dwell time, even though the experimental 
difference at around $40 \mathrm{~mm}$ between D250 and D750 is not as obvious as the modeling one, which could be caused by the above mentioned airflow interference ${ }^{26}$.
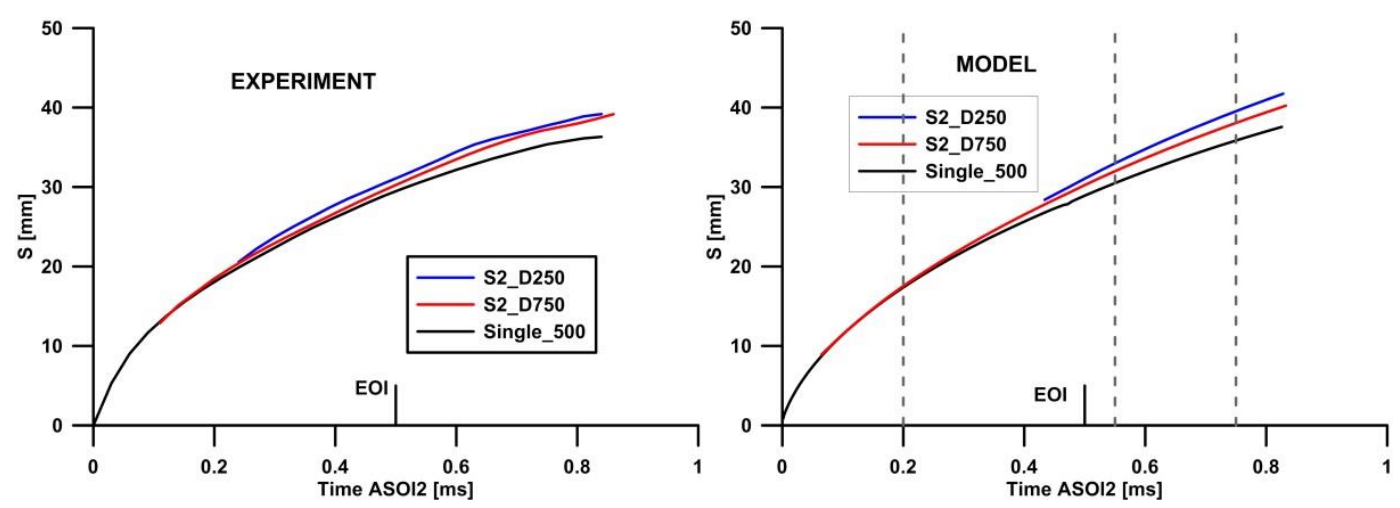

Fig. 10 Vapor penetration for the second injection pulse as a function of time ASOI2 from both experiment (left) and model (right) for dwell variation cases under nonreacting conditions. Vertical dashed lines correspond to the time positions at which modelling results are analyzed in Fig. 11. For the reference single injection case Single_500, time base is expressed after start of first injection (ASOI1).

In order to explain the penetration difference brought about by different dwell, a time sequence of the on-axis mixture fraction and the momentum flux along the spray axis corresponding to three time instants are shown in Fig. 11 (actual timings are also presented on the penetration plot in Fig. 10 as vertical dashed lines). Momentum flux is the main driver behind spray velocity field, while on-axis mixture fraction will provide information on the local mixture composition. For a top-hat injection profile, momentum flux is almost constant along the spray during the injection, while mixture fraction drops with a well know 1/x trend. This can be observed clearly for the single injection pulse at $200 \mu \mathrm{s}$ ASOI2. At the same timing but for a second injection pulse, the spray is injected into the remaining mixture from the first pulse. The boundary between first and second injection pulses can be identified easily from the step drop at around $18 \mathrm{~mm}$ in both onaxis mixture fraction and momentum flux curves. Because of the longer time after end of first injection and the corresponding larger entrained mass, the first injection pulse of the D750 case is leaner and with a lower momentum flux at the same timing ASOI2, as shown in Fig. 11 from around $17 \mathrm{~mm}$ to spray tip. For both D250 and D750 cases, the remaining momentum near the nozzle region from first injection is quite small, which does not bring a significant impact on the momentum exchange between the head of second injection and the tail of first injection. As a consequence, the difference of the second pulse penetration of D250 and D750 cases at this time is not so obvious, as shown in Fig. 10. In fact, the second pulse overlaps with the penetration of a single pulse with the same duration (Single_500) at the same time ASOI2.

At $550 \mu$ s ASOI2, second injection has just finished. The mass conservation requires a fast gas entrainment to compensate the decreasing fuel mass flux, which makes the mixture fraction and axis momentum near the nozzle decrease dramatically ${ }^{10}$. The entrainment wave starts propagating downstream with a much faster speed than the tip penetration rate ${ }^{11}$. Simultaneously, the tip of the second pulse approaches the zone where 
momentum left from the first injection is still present with non-negligible values. This results in the second pulse of the split injection cases penetrating faster than a single one (D250 and D750 vs Single_500), as the time to reach the quasi-steady momentum flux is reduced. This effect is more noticeable the shorter the dwell time, because of the higher momentum flux left by the first injection at the same timing ASOI. At $750 \mu \mathrm{s}$ ASOI2, the second pulse has almost reached the tip of the first one, with similar differences to the ones observed at $550 \mu \mathrm{s}$ ASOI2.
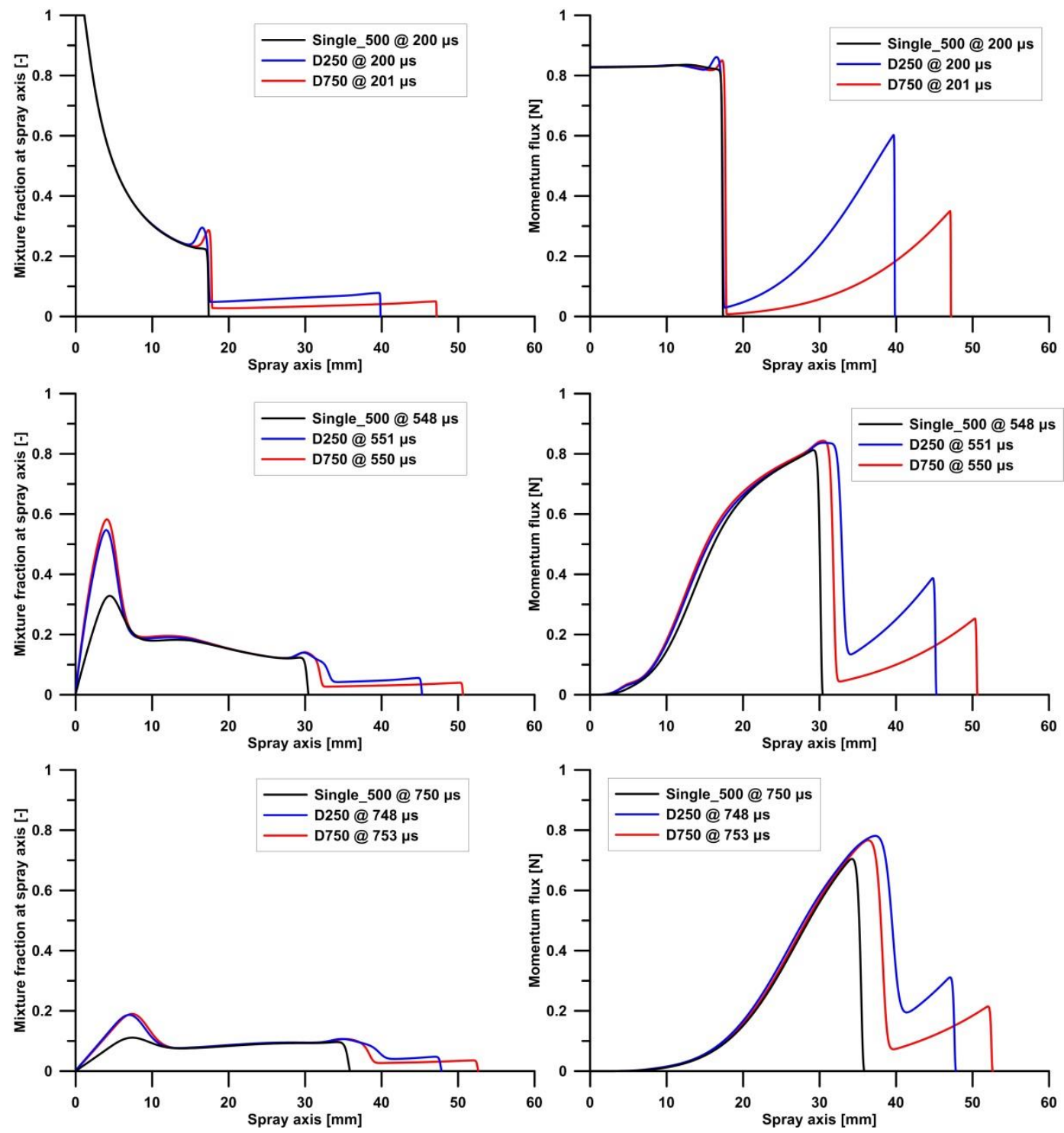

Fig. 11 On-axis mixture fraction (left column) and momentum flux (right column) of dwell time variation cases at time position $200 \mu \mathrm{s}$ ASOI2 (top), $550 \mu \mathrm{s}$ ASOI2 (middle) and $750 \mu \mathrm{s}$ ASOI2 (bottom). For Single_500 case, timing values are expressed after start of first injection (ASOI1).

Although experiments of F500 and F750 under non-reacting conditions have not been done, the 1D model is used here to analyze the effects of first injection on vapor penetration. Time evolution of vapor penetration of the second injection for F500 and 
F750 cases under non-reacting condition is shown in Fig. 12. The Single_1000 case is also presented here as a reference. Consistently with the dwell variation cases analyzed before, the second pulse penetrates faster than the single injection one after some axial distance away from the nozzle. However, Fig. 12 shows that the change on first injection duration does not seem to have an influence on the second injection penetration, when the dwell time is kept constant.

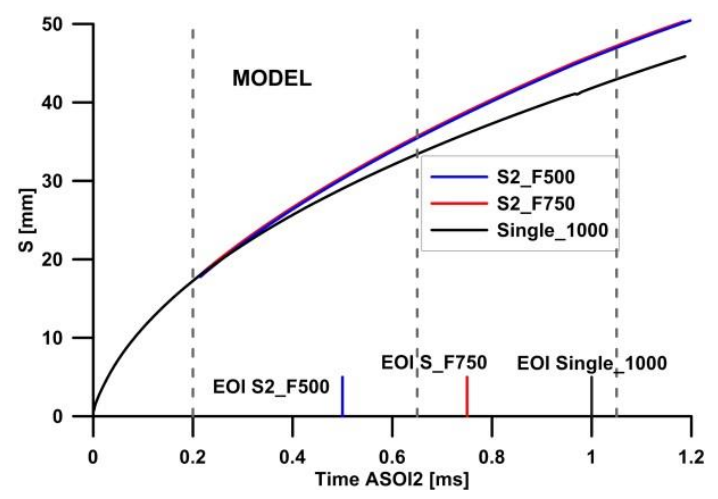

Fig. 12 Vapor penetration as a function of time ASOI2 from model (right) for first injection duration variation cases under non-reacting conditions. Vertical dashed lines correspond the time positions at which modelling results are analyzed in Fig. 13. For the reference single injection case Single_500, time base is expressed after start of first injection (ASOI1). 

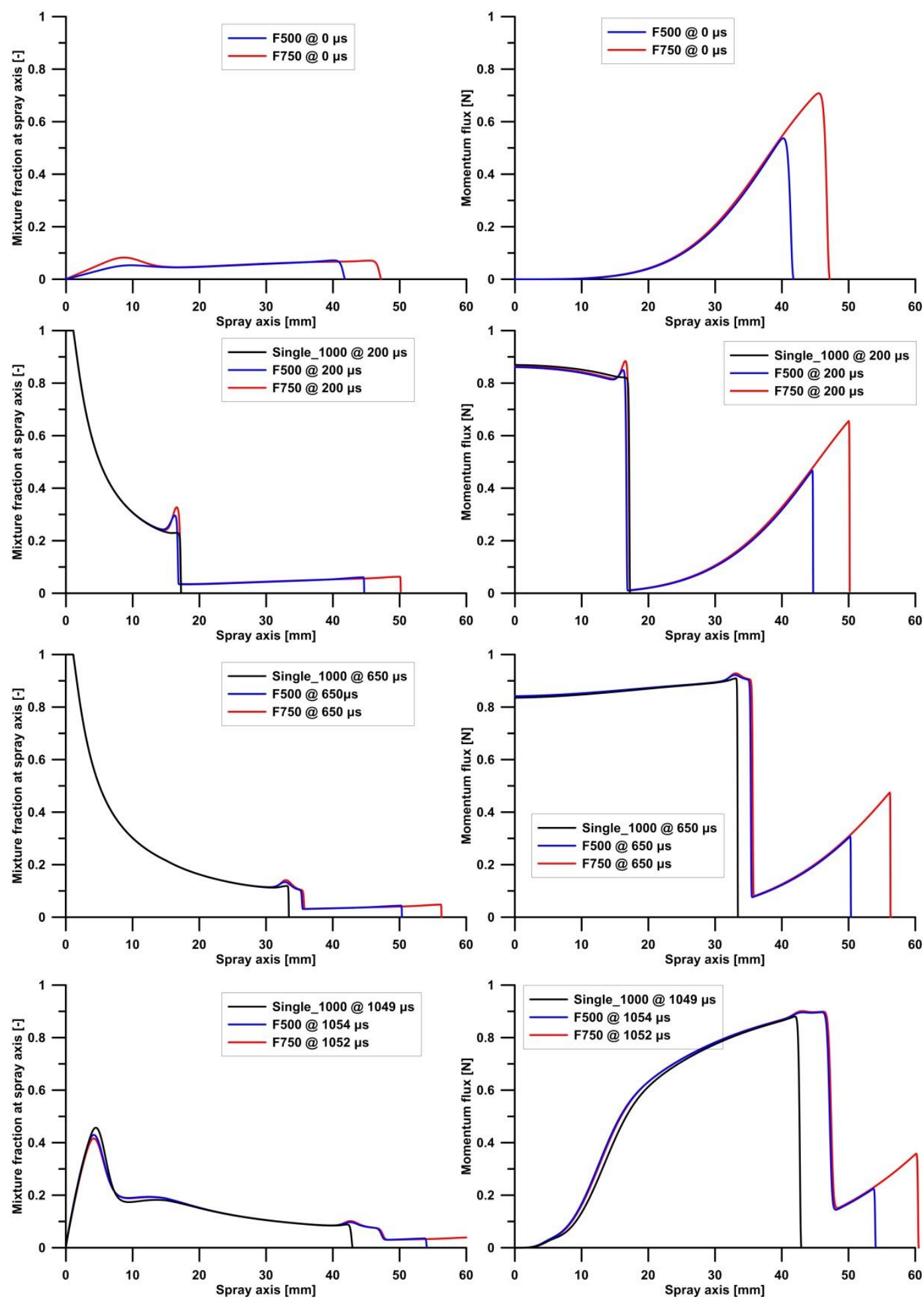

Fig. 13 On-axis mixture fraction (left column) and momentum flux (right column) of first injection duration variation cases at time position $0 \mu$ s ASOI2, 200 $\mu$ s ASOI2, $650 \mu \mathrm{s}$ ASOI2 and $1050 \mu$ s ASOI2 . For Single_1000 case, timing values are expressed after start of first injection (ASOI1). 
To analyze the previous result, a time sequence of on-axis mixture fraction and momentum flux along the spay axis of F500, F750 and the referenced Single_1000 are presented in Fig. 13. After the end of the first injection, the behaviour of the F500 and F750 is pretty similar, with the flow slowing down and leaning out from the nozzle downstream. Because of the quasi-steady structure of the preceding flow induced by a spray penetrating with a constant injection rate, differences caused by injection duration between F500 and F750 are only observed in the spatial region between the tip of F500 and F750. This structure is maintained at $200 \mu \mathrm{s} \mathrm{ASOI2,} \mathrm{where} \mathrm{the} \mathrm{second} \mathrm{injection} \mathrm{is}$ already proceeding, i.e. momentum and fuel mass distribution left from the previous injection are only different between 45 and $50 \mathrm{~mm}$. The second injection pulse eventually reaches locations where significant momentum values from first injection are present (650 $\mu \mathrm{s}$ ASOI2, $1050 \mu \mathrm{s}$ ASOI2). This will result in faster evolution of the second injection pulse. As a consequence, the difference of vapor tip penetration between single and double injection cases increases with time, as shown in Fig. 12.

\subsection{Reacting spray analysis}

\subsubsection{Combustion development}

A time sequence of processed Schlieren images for Single_1500 (left), D250 (middle) and D750 (right) cases under reacting conditions is shown in Fig. 14. For the single injection case, measured ignition delay is $630 \mu \mathrm{s}$. Therefore, combustion starts between the first two frames. For this single injection case, the quasi-steady LOL is stabilized near $15 \mathrm{~mm}$. As for split-injection cases, the first injection still behaves as an inert spray at $563 \mu \mathrm{s}$ ASOI, where injection has already come to the end, while the combustion starts before the second image at $763 \mu \mathrm{s}$ ASOI. It is interesting to note that, independently of the dwell between injection pulses, the most upstream location of the combustion products from the first injection remains around the LOL position. This effect could be caused by the 'entrainment wave' after the end of first injection, which slows down momentum flux, and hence local velocities. But it can also be amplified because of the radial expansion induced by combustion onset ${ }^{41,46}$. As discussed in the inert spray analysis, for the investigated condition the second injection pulse is penetrating into a flow field with very little momentum close to the nozzle, reaching the hot combustion products from the first injection, which causes a much faster ignition delay compared to the first pulse ${ }^{17,20}$. Consistently with ${ }^{17}$, LOL of the second injection pulse is also closer to the nozzle exit than that of first injection, as well as that of a single injection case (Single_1500). A similar result has been recently observed by Maes ${ }^{20}$, which has been explained in terms of the ignition location happening closer to the nozzle than for the first pulse. 

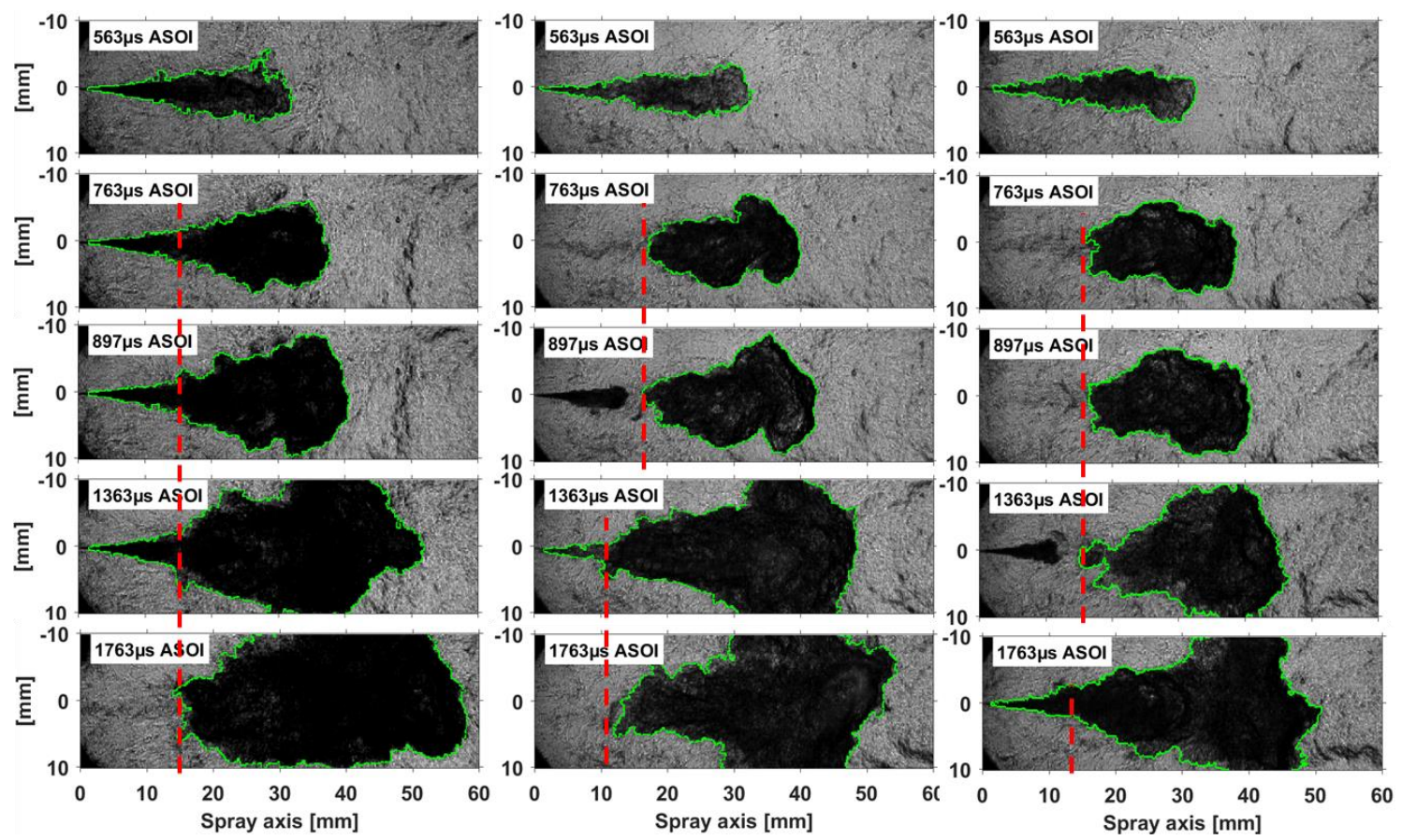

Fig. 14 Time sequence of Schlieren images for Single_1500 (left column) and D250 (middle column) and D750 (right column) cases under reacting conditions. Red vertical dashed lines represent LOLs.

The summary of effects of both dwell time and first injection duration on ignition delay and LOL are shown in Fig. 15. Considering the fact that the first injection duration of F500 is the same as D250 and D750 cases, as well as that the dwell time of F500 is $500 \mu \mathrm{s}, \mathrm{F} 500$ is included in the dwell variation as a reference. The Single_1500 case is also presented on the right plot as a reference for the variation of the first injection. As expected, the ID1 (ignition delay for the first injection) for all cases is pretty similar. Under such thermal condition $\left(870 \mathrm{~K}, 22.8 \mathrm{~kg} / \mathrm{m}^{3}\right)$, end of injection of the first injection pulse occurs before (D250, D750 and F500 cases) or after (F750 and Single_1500 cases) ignition delay. Therefore, injection duration does not seem to have an impact on the ignition delay of the first injection, ID1, consistently with previous work ${ }^{47}$ which shows that this parameter was not influenced by EOI at temperatures of $850 \mathrm{~K}$ and $900 \mathrm{~K}$.

Ignition delay of the second pulse (ID2) seems to be relatively insensitive to dwell time variation, with roughly $250 \mu$ s shorter values compared to ID1. As shown in the images, the upstream location of the combustion products for D250 and D750 is pretty similar (as shown in Fig. 14), and it does not shift downstream significantly with time probably because of the contrary airflow effect. A similar conclusion can be drawn from the images for the first injection duration variation (F500 vs F750, not shown here). Additionally, inert spray analysis has shown that the second injection of D250 penetrates faster than that of D750 only after $20 \mathrm{~mm}$ (Fig. 10), which is farther downstream than the combustion products location. As for the variation of first injection mass, differences are even less important. As a result, the second injection of all split injection cases reaches the hot combustion products at a similar time. Assuming that the reduced ignition delay of the second injection is due to the injection into this hot products cloud, where a higher 
temperature exist, the previous arguments indicate that ID2 should not be affected largely by neither dwell time, nor first pulse duration. A similar behavior is observed for LOL2 compared to that of the first injection, i.e. this parameter is not largely affected by dwell or first injection duration. Only a slight reduction of LOL2 (smaller than $2 \mathrm{~mm}$ ) is observed with shorter dwell time. The mechanism by which LOL2 is sensitive to dwell, while ID2 is not, is still an open point, which needs more input from detailed modelling.

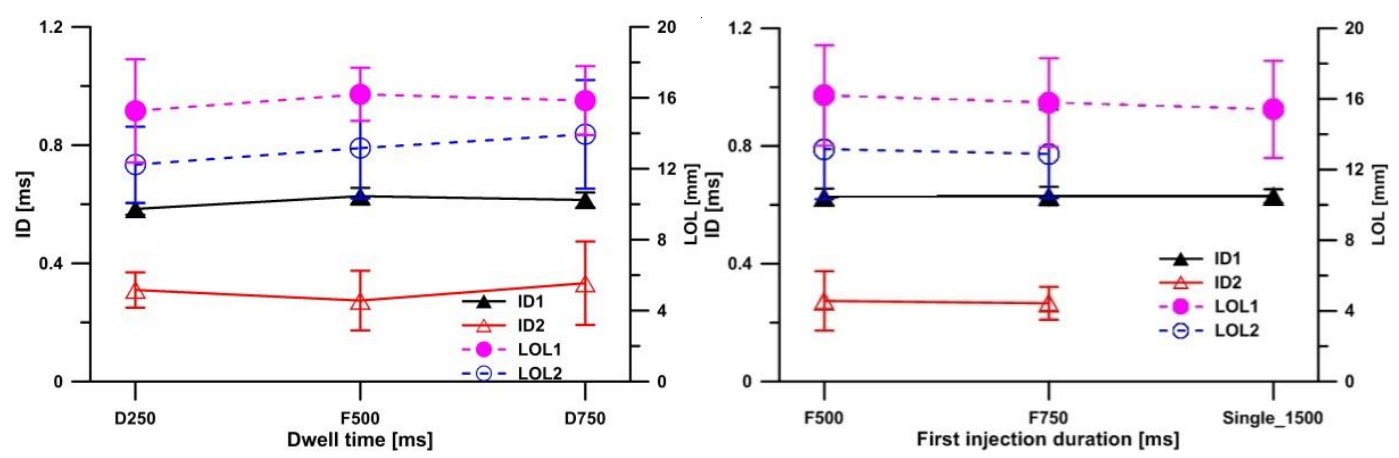

Fig. 15 Ignition delay and LOL of double injections for dwell time variation (left) and first injection duration variation (right). Symbols show average values, and error bars indicate standard deviation. (ID1, LOL1) and (ID2, LOL2) correspond to the first and second injection pulses, respectively.

\subsubsection{Instantaneous soot production}

Fig. 16 presents the $m_{\text {soot }}(x, t)$ plots and corresponding temporal evolution of total soot mass ( $m_{\text {soot }}(t)$ plot) of D250 and D750 cases. No soot can be observed for the first injection of either case, which can be explained by the fact that injection finishes before start of combustion. As previously discussed, the rapid air entrainment after EOI leans out the mixture before ignition to values too low to produce soot, which makes the equivalence ratio is not rich enough for soot formation. The modelled equivalence ratio of D250, D750 and F500 cases at the start of first-stage combustion should be same, as presented in Fig. 18(Left). Only a quite small part has an equivalence ratio higher than 2. According to the classic $\Phi$-T map ${ }^{48}$, equivalence ratio values higher than 2 are very favorable for soot formation. However, soot can be observed immediately after ID2 (vertical dashed line), which takes place before EOI2. It must be noted that while ignition delay is an averaged value from the sample of the cycle-resolved ignition delay, soot mass was calculated based on the averaged images. This can create some scattering between ID2 and soot onset time, as shown in Fig. 16 for D250 case. 

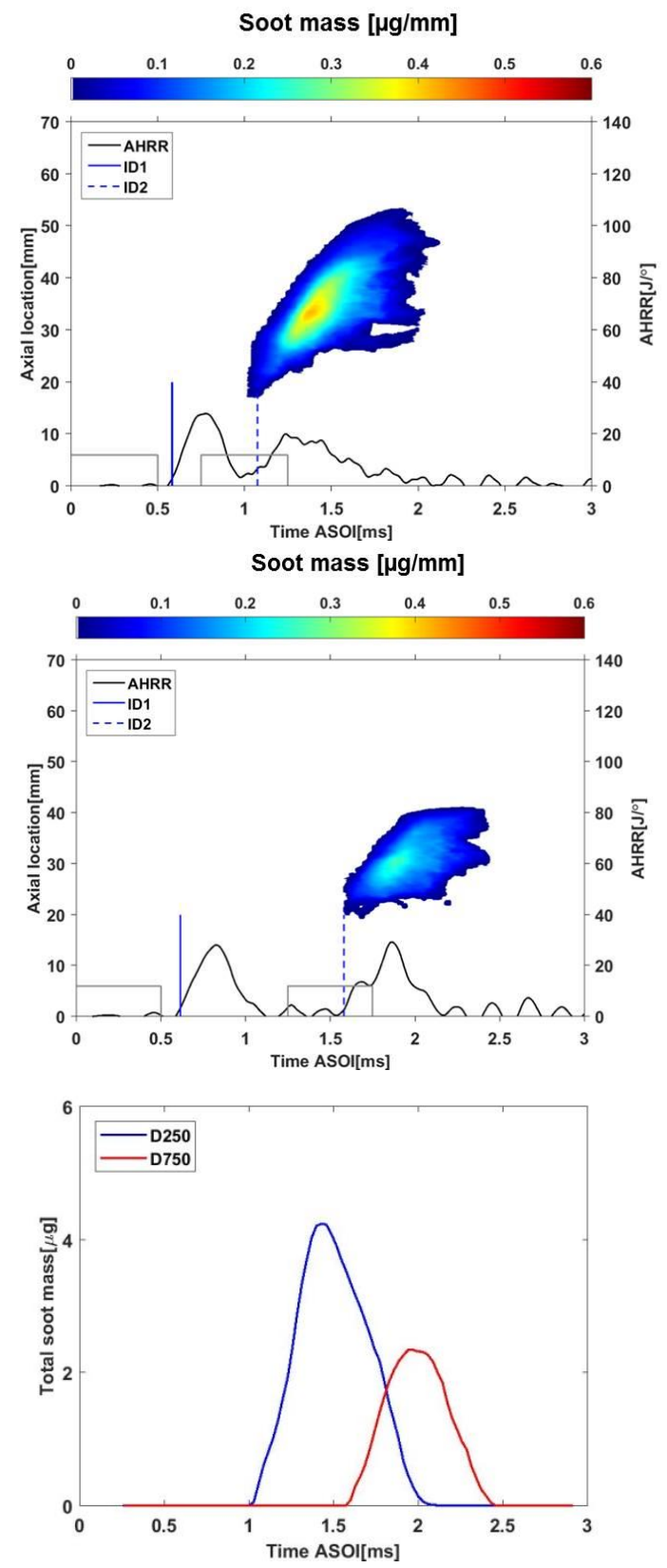

Fig. $16 \mathrm{~m}_{\text {soot }}(\mathrm{x}, \mathrm{t})$ plot , AHRR, ID1, ID2 of D250 (up) and D750 (middle) cases and corresponding temporal evolution of total soot mass (bottom)

From Fig. 16 one can conclude that the soot mass formed by the second injection pulse is larger with a shorter dwell time, which is consistent with the CFD results from ${ }^{23}$. As shown in the inert spray analysis, the equivalence ratio and momentum flux distribution of the spray during the initial stages of the second injection is not dependent on dwell. Under reacting conditions, combustion-induced radial expansion and slower mixing ${ }^{49}$ will create differences compared to the inert case, but this effect is essentially the same for both dwell cases, as demonstrated by the same ignition delay for both injection pulses. However, initial rise in heat release indicates faster chemical activity once combustion starts for the shorter dwell case, which may contribute to higher local 
temperatures and hence more soot production. Another possible contribution comes from the small reduction in LOL2 with shorter dwell, which will increase equivalence ratio at the flame base.

Fig. 17 presents the $m_{\text {soot }}(x, t)$ plots and $m_{\text {soot }}(t)$ plot of F500 and F750 cases. Consistently with D250 and D750 cases, no soot is formed during the first injection for F500 case. However, soot is present for the F750 case after a short dwell time from ID1. First, more fuel is injected and therefore more heat is released during the first-stage combustion for F750 case compared with F500, which will result in a more beneficial thermal condition for soot formation. Secondly, Fig. 17 clearly shows that the first ignition occurs after EOI for F500, while it occurs before EOI for F750. As mentioned above, the end of injection transient contributes to the reduction in local equivalence ratio a lot within a quite short time. The modelled equivalence ratio radius of both cases at SOC1 is presented in Fig. 18. Note that the spray model results have been obtained before start of combustion, which is applicable until this particular timing. Apparently, the fuel-rich mixture of F750 where the $\Phi$ is greater than 2 in the core spray area is much higher than that of F500. Therefore, the soot was detected during the first injection for F750 case.
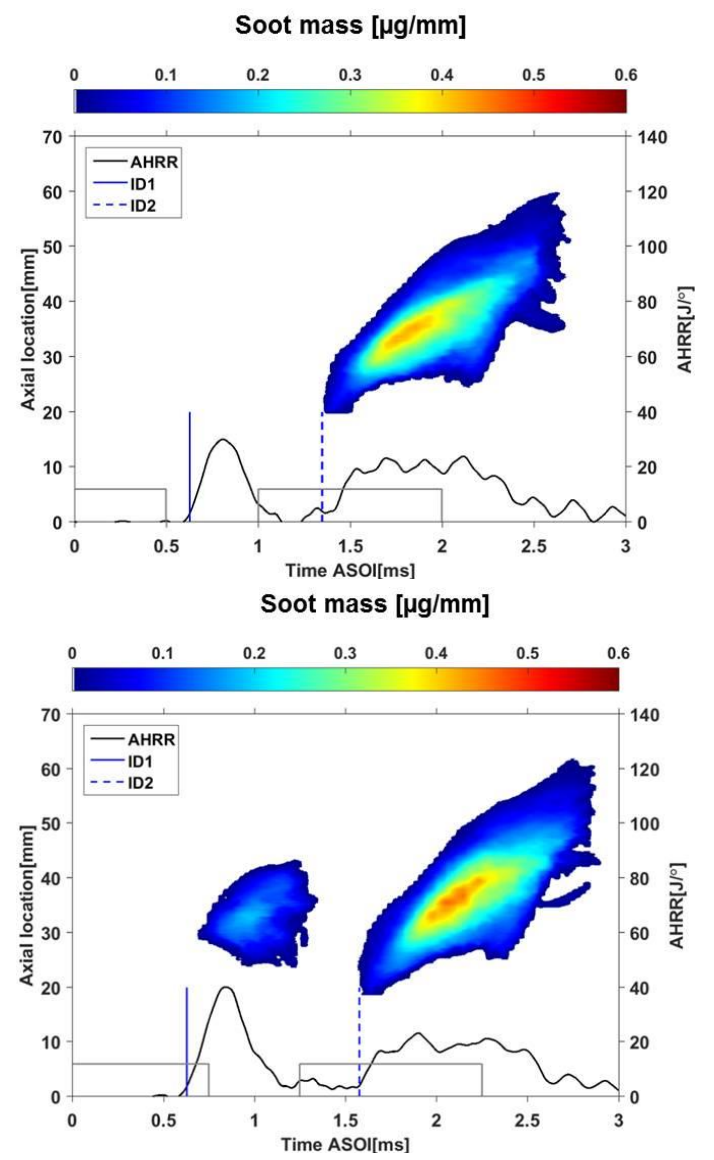


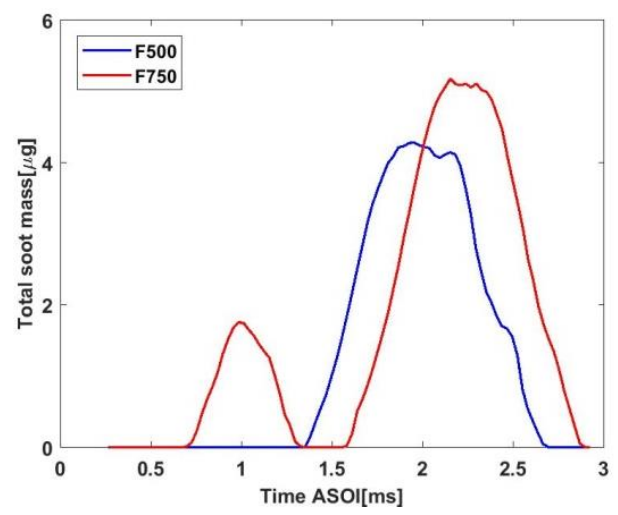

Fig. $17 \mathrm{~m}_{\text {soot }}(\mathrm{x}, \mathrm{t})$ plot , AHRR, ID1, ID2 of F500 (up) and F750 (middle) cases and corresponding temporal evolution of total soot mass (bottom)
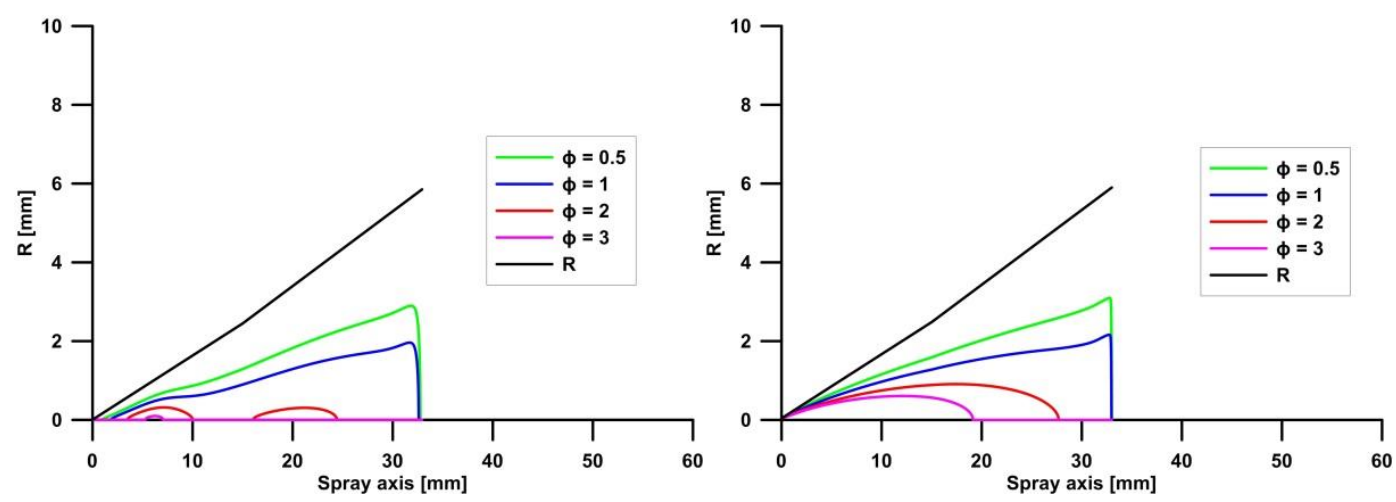

Fig. 18 Equivalence ratio radius of F500/D250/D750 (left) and F750 (right) cases at SOC1 from modeling. R represents the spray boundary.

As for the second injection pulse, results show that soot is formed immediately after ID2 for both F500 and F750 cases. Fig. 17 indicates that the soot cloud shapes of the second injection are quite similar for these two cases, which indicates they have similar temporal evolution of soot onset length and penetration. Furthermore, initial rise in the total soot mass plot is very similar for both cases, confirming an almost identical soot development in the second injection pulse, in agreement with the combustion development that has been previously analyzed. The main observed different is the fact that the maximum soot amount within the soot cloud for the F750 case is higher than in the F500, as confirmed by both the soot mass map as well as the integrated soot mass plot. Evolution around ignition location and during the early flame development is identical for F500/F750, pointing at similar equivalence ratio and temperature values. However, as the second pulse further progresses into the hot combustion products of the first one, it reaches locations where the larger injected mass of the first injection for F750 enables higher temperature levels compared to F250, and therefore more soot is formed.

Fig. 19 presents an overlap of the soot cloud contours derived from $m_{\text {soot }}(x, t)$ plots for all split-injection cases, together with a reference single case. For all splitinjection cases, the soot penetration of second injection penetrates faster than that of the single case, in agreement with the faster spray penetration shown from the inert tests. It 
can also be found that the soot onset position for the second injection is always closer to the injector than that of Single case. Furthermore, the trend of onset position between D250 and D750, and between F500 and F750 are consistent with LOL (LOLD250<=

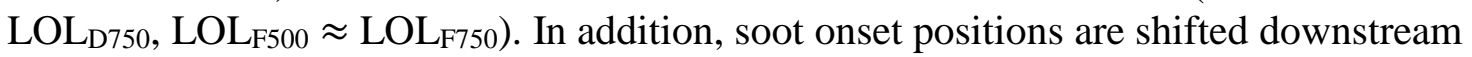
compared to LOL, which is consistent with the observation with chemiluminescence from ${ }^{17}$.
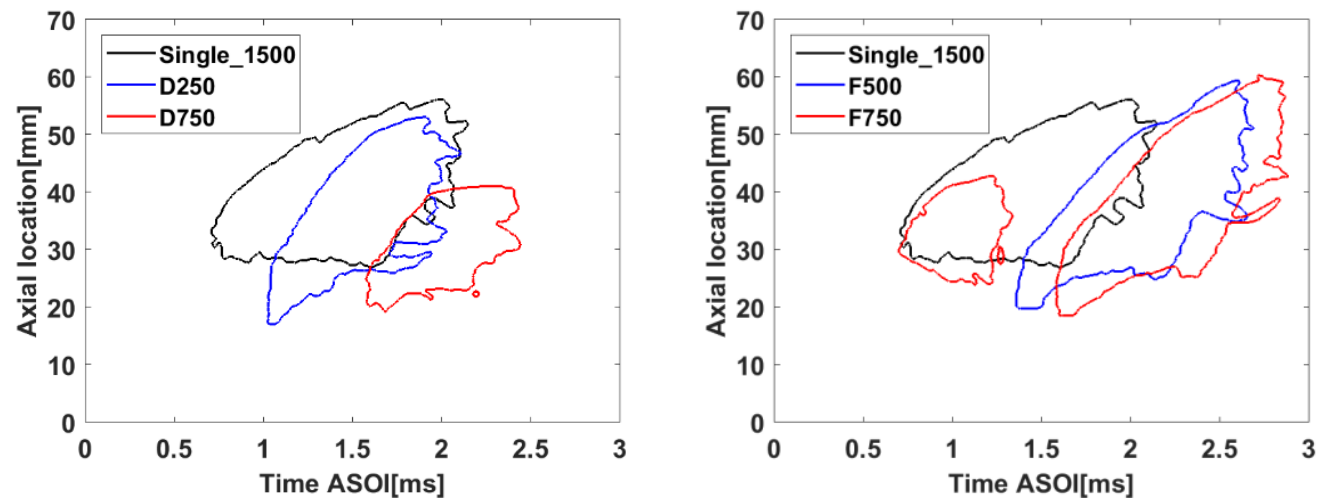

Fig. 19 Soot cloud contours derived from $m_{\text {soot }}(x, t)$ plots of Fig. 4, Fig. 16 and Fig. 17

\section{CONCLUSIONS}

Characteristics of non-reacting and reacting diesel spray with different split injection strategies were investigated in a single cylinder two-stroke optical diesel engine with n-dodecane as a fuel and with a single-hole injector. All the operating points were conducted under a constant TDC thermal condition with an ambient temperature equal to $870 \mathrm{~K}$, density equal to $22.8 \mathrm{~kg} / \mathrm{m}^{3}$. High-speed Schlieren imaging was applied for nonreacting spray measurements, while both Schlieren and DBI techniques were applied for reacting spray measurement. The AHRR was also derived from cylinder pressure trace to analyse the combustion process. In addition, a 1D spray model was also applied to back up the analysis. The effects of different dwell time and first injection duration on the fuelair mixing and combustion process of second injection were studied. Some important findings are summarized as follows:

- Under inert conditions the spray evolution has been investigated by means of both experiments and 1D spray model, to evaluate the evolution of the mixing process.

- For the investigated dwell time variation (D250, D750), the second injection penetrates faster with a shorter dwell time when the injection durations were kept same. Although the initial evolution close to the nozzle is almost independent of dwell, as the spray grows it reaches a zone where flow from the first injection is still present. With shorter dwell time, a higher momentum remains from first injection, which creates a faster accommodation of the flow to the second injection, and therefore a faster penetration. 
O As for the first injection duration variation (F500, F750), there is no difference on the remaining momentum from first injection in the vicinity of the nozzle, with differences being found at the spray tip. For the investigated conditions the second pulse never reaches the tip of the first one within the observation window. At least within such conditions, modelling results indicate that the penetration of second injection is essentially independent of injection duration.

- The ignition delay of the second injection (ID2) is reduced roughly by a factor of two compared with the first one. Considering the similar penetration before 20 $\mathrm{mm}$ and similar lift-off length, the second injection spray pulse enters the cloud of combustion products from first injection at a similar timing. Even though the combustion products temperature of D750 might be lower than that of D250, the temperature is still high enough to ignite the second injection as soon as the second pulse penetrates into the combustion products remaining from the first injection, which results in a low sensitivity of ID2 to dwell. Therefore, bringing the fuel to the location of the first injection combustion products seems to be the main mechanism for the second injection to ignite. Consistently with this result, the lift-off length of the second injection (LOL2) shows very little sensitivity to dwell, with a slightly shorter dwell igniting closer to the nozzle.

- Neither ignition delay nor lift-off length for the second injection seems to be affected by the duration of the first injection. This confirms that the relevant mechanism to ignite the second spray is bringing the mixture to the first injection combustion location.

- In terms of soot, no soot has been observed for a first injection duration of $500 \mu \mathrm{s}$ (D250, D750 and F500), because of the fuel-lean mixture caused by the fast air entrainment after the end of injection. One the other hand, soot was detected for F750 case because of the much higher equivalence ratio at start of ignition compared with other cases, due to the injection and combustion overlap.

- With a shorter dwell time, the faster initial heat release after ignition of the second injection induces higher temperature of combustion products, which contributes to a higher soot production in the second injection pulse.

- At the beginning-stage of soot formation of second injection, F500 and F750 cases keep a similar soot production rate, which is caused by the similar equivalence ratio, temperature and similar LOL2 around ignition location and during the early flame development. However, as the second pulse further progresses into the hot combustion products of the first one, it reaches locations where the larger injected mass of the first injection for F750 enables higher temperature levels compared to F250, and therefore more soot is formed.

\section{ACKNOWLEDGEMENTS}

This study was partially funded by the Spanish Ministry of Economy and

Competitiveness in the frame of the COMEFF (TRA2014-59483-R) project. Funding for 
Tiemin Xuan's PhD studies was granted by Universitat Politècnica de València thorugh the Programa de Apoyo para la Investigación y Desarrollo (PAID) (Grant reference FPI2015-S2-1068).

\section{REFERENCES}

1. Han Z., Uludogan A., et al., Mechanism of Soot and NOx Emission Reduction Using Multiple-injection in a Diesel Engine. SAE paper 960633, 1996.

2. Chen S., Simultaneous Reduction of NOx and Particulate Emissions by Using Multiple Injections in a Small Diesel Engine. SAE paper 2000-01-3084, 2000.

3. Benajes J., Molina S., and García J., Influence of Pre- and Post-Injection on the Performance and Pollutant Emissions in a HD Diesel Engine. SAE paper 2001-01-0526, 2001.

4. Osada H., Uchida N., et al., Reexamination of Multiple Fuel Injections for Improving the Thermal Efficiency of a Heavy-Duty Diesel Engine. SAE paper 2013-01-0909, 2013.

5. Arrègle J., Pastor J., et al., Insights on postinjection-associated soot emissions in direct injection diesel engines. Combust. Flame 2008;154:448-461.

6. Desantes J., Arrègle J., et al., A Comprehensive Study of Diesel Combustion and Emissions with Post-injection. SAE paper 2007-01-0915, 2007.

7. Mendez S. and Thirouard B., Using Multiple Injection Strategies in Diesel Combustion: Potential to Improve Emissions, Noise and Fuel Economy Trade-Off in Low CR Engines. SAE Int. J. Fuels Lubr. 2009; 1: 662-674.

8. He Z., Xuan T., et al., Study on Effect of Fuel Injection Strategy on Combustion Noise and Exhaust Emission of Diesel Engine. Thermal Science 2013;17:81-90.

9. Musculus M., Lachaux T., et al., End-of-Injection Over-Mixing and Unburned Hydrocarbon Emissions in Low-Temperature-Combustion Diesel Engines. SAE paper 2007-01-0907, 2007.

10. Kook S., Pickett L., and Musculus M., Influence of Diesel Injection Parameters on End-ofInjection Liquid Length Recession. SAE Int. J. Engines 2009; 2:1194-1210

11. Musculus M. and Kattke K., Entrainment Waves in Diesel Jets. SAE Int. J. Engines 2009; 2: 1170-1193.

12. O'Connor J., Musculus M., and Pickett L., Effect of post injections on mixture preparation and unburned hydrocarbon emissions in a heavy-duty diesel engine. Combust. Flame 2016; 170: 111-123.

13. O'Connor J., and Musculus M., Post Injections for Soot Reduction in Diesel Engines: A Review of Current Understanding. SAE Int. J. Engines 2013; 6: 400-421

14. O'Connor J., and Musculus M., In-Cylinder Mechanisms of Soot Reduction by CloseCoupled Post-Injections as Revealed by Imaging of Soot Luminosity and Planar LaserInduced Soot Incandescence in a Heavy-Duty Diesel Engine. SAE Int. J. Engines 2014; 7 : 673-693. 
15. Bruneaux G., and Maligne D., Study of the Mixing and Combustion Processes of Consecutive Short Double Diesel Injections. SAE Int. J. Engines 2009; 2: 1151-1169.

16. Pickett L., Kook S., and Williams T., Transient Liquid Penetration of Early-Injection Diesel Sprays. SAE Int. J. Engines 2009; 2: 785-804

17. Skeen S., Manin J., and Pickett L., Visualization of Ignition Processes in High-Pressure Sprays with Multiple Injections of n-Dodecane. SAE Int. J. Engines 2015; 8

18. Bolla M., Chishty M., et al, Modeling combustion under engine combustion network Spray A conditions with multiple injections using the transported probability density function method. Int. J. Engine Res. 2017;18: 6-14

19. Blomberg C., Zeugin L., et al., Modeling Split Injections of ECN "Spray A" Using a Conditional Moment Closure Combustion Model with RANS and LES. SAE Int. J. Engines 2016; 9: 21072119.

20. Maes N., Bakker P., et al., Transient Flame Development in a Constant-Volume Vessel using a Split-Scheme Injection Strategy. SAE Int. J. Fuels Lubr. 2017; 10.

21. Cung K. S., et al., Spray-combustion interaction mechanism of multiple-injection under diesel engine conditions. Proc. Combust. Inst. 2015; 3061-3068.

22. Moiz A., Cung KD., Lee S., Simultaneous Schlieren-PLIF Studies for Ignition and Soot Luminosity Visualization With Close-Coupled High-Pressure Double Injections of nDodecane. ASME. J. Energy Resour. Technol. 2017; 139.

23. Moiz A., Ameen M., et al., Study of soot production for double injections of $n$-dodecane in $\mathrm{Cl}$ engine-like conditions. Combust. Flame 2016; 173: 123-131.

24. Pastor J.V., López J.J., et al., A 1D Model for the Description of Mixing-Controlled Inert Diesel Sprays. Fuel 2008; 87: 2871-2885.

25. Pastor J.V., López J.J., et al., A 1D Model for the Description of Mixing-Controlled Reacting Diesel Sprays. Combust. Flame 2009; 156: 234-249.

26. Pastor J.V., García J.M., et al., An experimental study on Diesel spray injection into a nonquiescent chamber. SAE Int. J. Fuels Lubr. 2017; 10.

27. Bermúdez, V., García, J., et al., Engine with Optically Accessible Cylinder Head: A Research Tool for Injection and Combustion Processes. SAE paper 2003-01-1110, 2003.

28. Settles G. S., Schlieren and sadowgraph techniques: visualizing phenomena in transparent media (Experimental Fluid Mechanic). Springer Verlag, Heidelberg, Germany, 2001

29. Pastor J.V., Payri R., et al., Schlieren Methodology for the Analysis of Transient Diesel Flame Evolution. SAE Int. J. Engines 2013; 6:1661-1676.

30. Pastor J.V., García J.M., et al., Soot Quantification of Single-Hole Diesel Sprays by Means of Extinction Imaging. SAE Int. J. Engines 2015; 8: 2068-2077.

31. Pickett L.M., and Siebers D.L., Soot in diesel fuel jets: effects of ambient temperature, ambient density, and injection pressure. Combust. Flame 2004; 138: 114-135. 
32. Koylu U.O., and Faeth G.M., Optical properties of overfire soot in buoyant turbulent diffusion flames at long residence times. Journal of heat transfer 1994; 116:152-159.

33. Manin J., Pickett L., and Skeen S., Two-Color Diffused Back-Illumination Imaging as a Diagnostic for Time-Resolved Soot Measurements in Reacting Sprays. SAE Int. J. Engines 2013; 6:1908-1921.

34. Choi, M., Mulholland, G., et al., Comparisons of the soot volume fraction using gravimetric and light extinction techniques. Combust. Flame, 1995; 102: 161-169.

35. Engine Combustion Network webpage. http://www.sandia.gov/ecn (accessed 25 July 2017).

36. Manin J., Bardi M., and Pickett L., Evaluation of the liquid length via diffused back-illumination imaging in vaporizing diesel sprays. International Symposium COMODIA, 2012

37. Heywood J.B., Internal Combustion Engine Fundamentals. McGraw-Hill, 1988.

38. Tauzia X., Maiboom A., and Ma G., A 1D Model for Diesel Sprays under Reacting Conditions. SAE paper 2015-24-2395, 2015.

39. Knox B.W. and Genzale C.L., Reduced-order numerical model for transient reacting diesel sprays with detailed kinetics. Int. J. Engine Res. 2015; 17: 261-279.

40. Burke S.P. and Schumann. T. E. W., Diffusion flames. Ind. Eng. Chem. Res. 1928; 20: 9981005.

41. Desantes J.M., García-Oliver J.M., et al., A study on tip penetration velocity and radial expansion of reacting diesel sprays with different fuels. Fuel 2017; 207: 323-335.

42. Nerva J. G., An assessment of fuel physical and chemical properties in the combustion of a Diesel spray. PhD Thesis, Universitat Politècnica de València, Spain, 2013

43. Bosch W., The fuel rate indicator: a new instrument for of the characteristic of individual injection. SAE paper 660749, 1966.

44. Payri R., Salvador F.J., et al., A new methodology for correcting the signal cumulative phenomenon on injection rate measurements. Exp Tech 2008; 15: 46-49.

45. Payri R., Gimeno J., et al., On the rate of injection modeling applied to direct injection compression ignition engines. Int. J. Engine Res. 2016; 17: 1015 -1030.

46. Payri R., García J.M., et al., A study on diesel spray tip penetration and radial expansion under reacting conditions. Appl.Therm.Eng.2015; 90: 619-629.

47. Malbec L., Eagle W., et al., Influence of Injection Duration and Ambient Temperature on the Ignition Delay in a 2.34L Optical Diesel Engine. SAE Int. J. Engines 2016; 9: 47-70.

48. Kamimoto T., and Bae M., High Combustion Temperature for the Reduction of Particulate in Diesel Engines. SAE paper 880423, 1988.

49. García J.M., Malbec L.M., et al., A study on the interaction between local flow and flame structure for mixing-controlled diesel sprays. Combust. Flame 2017; 179: 157-171 